\title{
ANALISIS KESESUAIAN DAN DAYA DUKUNG EKOWISATA PANTAI KATEGORI REKREASI PANTAI LAGUNA DESA MERPAS KABUPATEN KAUR
}

\author{
Oleh \\ Eka Noerma Yulisa*, Yar Johan dan Dede Hartono \\ Program Studi Ilmu Kelautan Fakultas Pertanian Universitas Bengkulu, Bengkulu \\ *Email: ekanoermayulisa95@gmail.com \\ Received March 2016, Accepted April 2016
}

\begin{abstract}
ABSTRAK
Pantai Laguna terletak di Desa Merpas, Kecamatan Nasal, Kabupaten Kaur. Pantai ini merupakan pantai yang memiliki daya tarik berupa pantai karang berpasir putih yang landai dengan pemandangan bawah laut yang indah. Penelitian ini dilaksanakan di Desa Merpas Kabupaten Kaur, pada bulan Desember 2015 sampai Januari 2016 dan bertujuan untuk Mengidentifikasi potensi Kawasan Ekowisata Pantai Laguna, Mengetahui kesesuaian Ekowisata Pantai Laguna sebagai Ekowisata Pantai, Menghitung daya dukung Ekowisata Pantai Laguna untuk menjadi kawasan Ekowisata Pantai. Metode yang digunakan yaitu data primer pengambilan data analisis kualitas air, metode penentuan kesesuaian kawasan berdasarkan perkalian skor dan bobot yang diperoleh dari setiap paremeter, kedalaman, tipe pantai, lebar pantai, kecerahan, kecepatan arus, material dasar perairan, pengamatan biota berbahaya, dan ketersediaan air tawar. Berdasarkan hasil penelitian di lapangan Potensi ekowisata pantai di Pantai Laguna ada dua kategori yaitu 1) ekowisata kategori rekreasi untuk indeks kesesuaian kawasan kategori ekowisata rekreasi yaitu $90,6 \%$ S1 (sangat sesuai). Daya dukung kawasan kategori ekowisata rekreasi 224 (Orang/hari).
\end{abstract}

Kata kunci : Ekowisata pantai, kesesuaian kawasan, daya dukung kawasan, pantai laguna

\begin{abstract}
Laguna Beach is located in the village of Merpas, District Nasal, District Kaur. This beach is the beach which has the attractiveness of white sandy beaches sloping reef with underwater scenery is beautiful. This research was conducted in the village Merpas Kaur District, in December 2015 through January 2016 and aims to identify potential Ecotourism Region Laguna Beach, Laguna Beach Knowing Ecotourism suitability as Ecotourism Beach, Ecotourism Calculating carrying capacity of Laguna Beach to be Ecotourism Coast region. The method used is primary data retrieval of data analysis of water quality, the method of determining the suitability of the area by multiplying scores and weights were obtained from each parameter, depth, type of beach, wide beach, brightness, current speed, basic materials waters, observation biota dangerous, and availability freshwater. Based on the results of research in the field of ecotourism potential of the beach in Laguna Beach two categories: 1) ecotourism recreation category, for suitability index recreation area ecotourism category ie $90.6 \%$ S1 (very appropriate),. Analysis of the carrying capacity of the area recreational ecotourism category 224 (person / day).
\end{abstract}

Key words : Ecotourism beach, conformity regions, carrying capacity,laguna beach 


\section{PENDAHULUAN}

Bidang kelautan memiliki sumberdayahati dan sumberdaya non hayati seperti sektor jasa kelautan, perikanan, pertambangan laut, industri maritim, dan perhubungan laut. Sektor tersebut dapat menjadi salah satu andalan ekowisata Indonesia. Dengan melandaskan pada aspek eksplorasi, konservasi, dan pengelolaan secara terpadu, Salah satu aspek pembangunan pada bidang ekowisata diharapkan mampu mewujudkan pengelolaan ekosistem secara berkelanjutan adalah melalui pengembangan ekowisata (Fandeli, 2000).

Ekowisata mulai mengarah pada pelestarian lingkungan dan ekologis yang sering disebut dengan ekowisata di era globalisasi ini. Sehingga perlu digali dan dikembangkan guna menjadikan wisatawan sadar dan peduli akan lingkungan. Ekowisata di suatu daerah memiliki banyak manfaat, baik dalam segi ekonomi, ekologi, maupun sosial budaya (Kementerian Kebudayaan dan Pariwisata Indonesia, 2002).

Pengembangan industri wisata dijadikan sebagai salah satu strategi yang dipakai oleh pemerintah bahkan swasta untuk mempromosikan wilayah tertentu sebagai daerah tujuan wisata guna meningkatkan perekonomian dan kesempatan kerja. Upaya pengembangan wisata terkait potensi pasar kedepan dimana World Tourism Organization (WTO) memperkirakan bahwa pada tahun 2020 akan terjadi peningkatan sebesar $1.561,1$ juta orang dengan pertumbuhan tertinggi di Asia-Pasifik sebesar 6,5\% (Budhyana, 2008).

Wilayah pesisir dan laut yang dapat dikembangkan menjadi kawasan wisata berupa pemandangan pantai yang indah dan keaslian lingkungan seperti kehidupan di bawah air. Pengembangan pantai sebagai tempat ekowisata merupakan jasa lingkungan dari alokasi sumberdaya yang cenderung akan memberikan manfaat pada kepuasan batin seseorang dikarenakan mengandung nilai estetika tertentu (Ali, 2004).

Berdasarkan kemajuan ilmu pengetahuan dan teknologi sehingga memudahkan wisatawan menentukan destinasi wisatanya dengan model pengembangan ekowisata alam yang bertanggung jawab di daerah yang di tujunya. Selain untuk menikmati keindahan alam juga melibatkan unsur pendidikan dan dukungan terhadap usaha konservasi serta secara terbuka maupun yang belum dikenal secara terbuka. Kegiatan ekowisata diharapkan berdampak positif terhadap kelestarian lingkungan dan meningkatkan perekonomian masyarakat lokal.

Kaur adalah salah satu Kabupaten yang ada di Provinsi Bengkulu. Terletak sekitar 250 km dari Kota Bengkulu Kabupaten Kaur juga memiliki potensi ekowisata pantai diantaranya, Pantai Hili, Pantai Putri Dayang Pandan, Pantai Bunga Karang, Pantai Linau dan Pantai Laguna. Pantai Laguna terletak di Desa Merpas, Kecamatan Nasal, Kabupaten Kaur memiliki jarak sekitar 30 km kearah selatan dari Kota Bintuhan. Pantai ini merupakan pantai yang memiliki daya tarik berupa pantai karang berpasir putih yang landai dengan pemandangan bawah laut yang menawan. Untuk pemanfaatan dan pengelolaan potensi Ekowisata yanga ada di pantai laguna perlu dilakukan penelitian terkait tentang Analisis Kesesuaian dan Daya Dukung Ekowisata Pantai Kategori Rekreasi Laguna Kabupaten Kaur.

\section{Waktu dan Tempat Penelitian}

\section{METODE PENELITIAN}

Kegiatan penelitian ini dilaksanakan dari bulan Desember 2015- Januari 2016 di Pantai Laguna Kabupaten Kaur ( Gambar 1). 


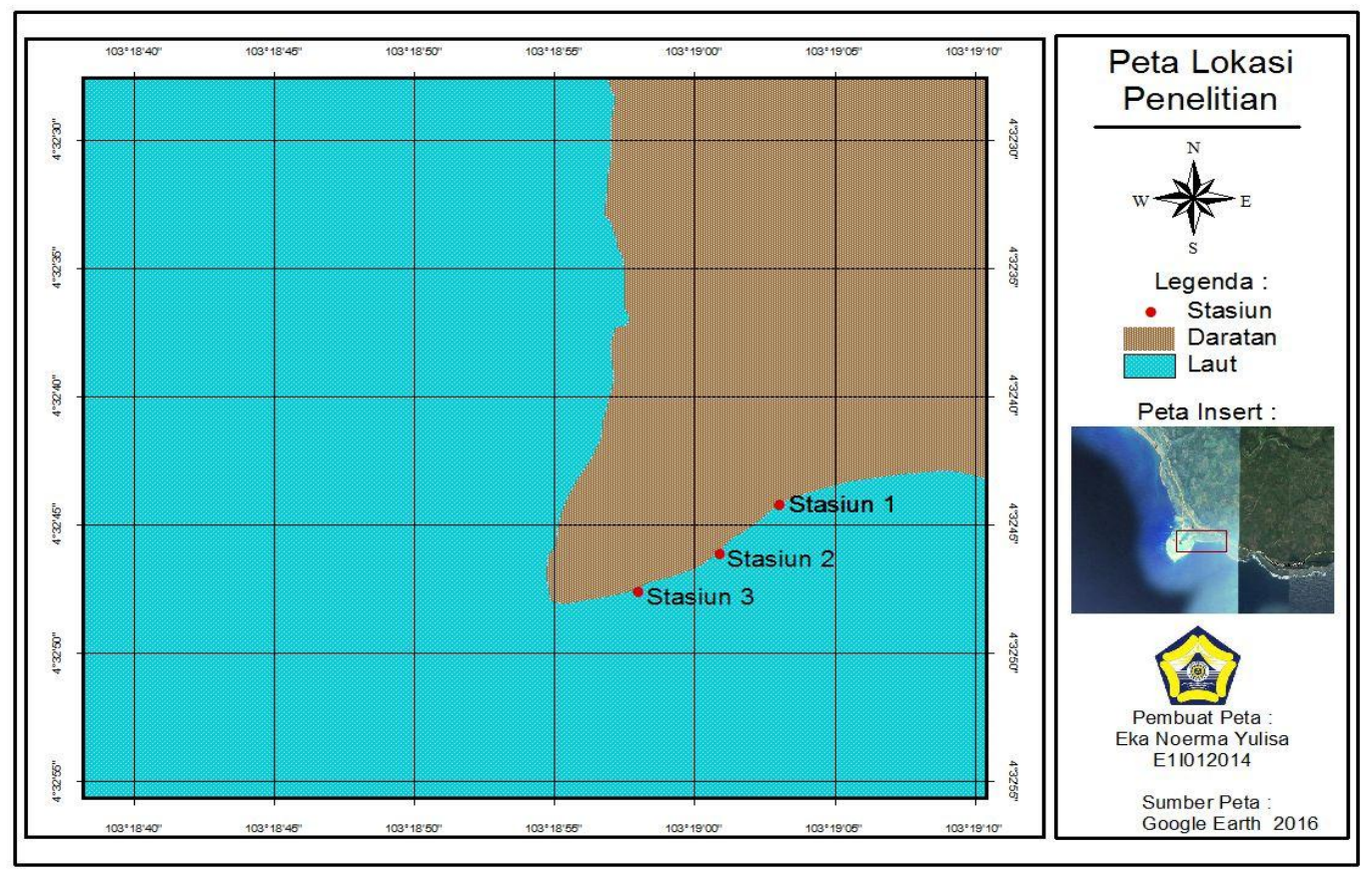

Gambar 1. Peta Lokasi Penelitian

Sumber peta Google earth (2016)

Penelitian ini, menggunakan teknik purpossive untuk penentuan stasiun. Pertimbangan menggunakan metode penentuan stasiun pengamatan mengunakan teknik purposive karena purposive adalah teknik pengambilan sampel sumber data dengan pertimbangan tertentu (Safina, dkk 2014). Titik Koordinat Stasiun Penelitian di Pantai Laguna ( Tabel 1).

Tabel 1. Titik Kooordinat Stasiun Penelitian

No Titik Sampling Titik Koordinat

\begin{tabular}{lll}
\hline 1 & Stasiun 1 & $04^{0} 54^{\prime} 958^{\prime} \mathrm{S} 103^{0} 37.088^{\prime} \mathrm{T}$ \\
2 & Stasiun II & $04^{0} 54^{\prime} 987^{\prime} \mathrm{S} 103^{0} 32.032^{\prime} \mathrm{T}$ \\
3 & Stasiun III & $04^{0} 54^{\prime} 998^{\prime} \mathrm{S} 103^{0} 31.979^{\prime} \mathrm{T}$ \\
\hline
\end{tabular}

Alat dan Bahan

Alat dan kegunaan pada saat penelitian dapat dilihat pada Tabel 2.

Tabel 2. Alat dan Bahan penelitian.

\begin{tabular}{lll}
\hline No & Alat & Kegunaan \\
\hline 1 & Alat tulis & Mencatat hasil pengamatan dilapangan. \\
2 & Kuisoner & Sebagai daftar pertanyaan \\
3 & Kamera & Dokumentasi kegiatan \\
4 & Rol Meter & Mengukur panjang pantai dan Lebar pantai \\
5 & Parasut arus & Mengukur kecepatan arus \\
6 & Alat snorkeling & Pengamatan biota berbahaya \\
7 & GPS (global positioning system) & Menentukan titik koordinat titik sampling \\
8 & Secchi disk & Mengukur kecerahan \\
9 & Laptop & Sebagai pengolah data \\
10 & Literatur lainnya & Data sekunder untuk mendukung penelitian \\
\hline
\end{tabular}




\section{Sumber Data}

Data primer adalah data yang langsung diperoleh dari lapangan, mengukur Kecerahan, Tipe Pantai, Lebar pantai, Material Dasar Perairan, Kecepatan Arus Biota Berbahaya, Ketersedian Air Tawar. Dalam penelitian ini data juga diperoleh dari jawaban responden yang ada di obyek ekowisata Pantai Laguna Kabupaten Kaur, terhadap wawancara pengisian kuesioner yang disampaikan langsung oleh peneliti.

Data sekunder diperoleh dari Dinas pariwisata Kabupaten Kaur, Jurnal, Tesis, Buku, Dinas Kelautan Perikanan (DKP), Wisatawan, Kepala Desa, Tokoh Masyarakat, Pemuda, Nelayan, Badan Pusat Statistik (BPS), Dinas Kehutanan, Dinas Pariwisata Kabupaten Kaur.

\section{Metode Pengumpulan Data \\ Data Paremeter Ekowisata Pantai Rekreasi. Kedalaman}

Pengukuran kedalaman pada penelitian ini menggunakan alat rambu ukur/tiang skala. Nilai yang ditunjukkan pada tiang skala ini merupakan nilai kedalaman stasiun penelitian dan penentuan kedalaman 10 meter darigaris pantai (Masita $d k k, 2013$ ).

\section{Tipe pantai}

Penentuan tipe pantai dan material dasar perairan dilakukan berdasarkan pengamatan visual di lapangan (Masita $d k k, 2013$ ).

\section{Lebar Pantai}

Pengukuran lebar pantai dilakukan dengan menggunakan roll meter, yaitu diukur jarak antara vegetasi terakhir yang ada di pantai dengan batas pasang tertinggi (Masita $d k k, 2013$ ).

\section{Material Dasar perairan}

Penentuan tipe pantai dan material dasar perairan dilakukan berdasarkan pengamatan visual di lapangan (Masita $d k k, 2013$ ).

\section{Kecepatan Arus}

Nybakken (1992) menyatakan bahwa Kecepatan arus diukur menggunakan layang-layang arus, yakni dengan menetapkan jarak tempuh layang-layang arus (5 meter) kemudian diukur waktu tempuh layang-layang arus tersebut. Perhitungan kecepatan arus menggunakan rumus :

\section{Keterangan:}

$$
\mathrm{V}=\mathrm{S} / \mathrm{T}
$$

$\mathrm{V}=$ Kecepatan Arus

$\mathrm{S}=$ Panjang lintasan parasut arus $(\mathrm{m})$

$\mathrm{t}=$ Waktu tempuh layang - layang arus (detik)

\section{Kecerahan}

Pengukuran kecerahan dilakukan dengan menggunakan secchi disk yang diikat dengan tali kemudian diturunkan perlahan-lahan ke dalam perairan pada lokasi pengamatan sampai pada batas visual secchi disk tersebut tidak dapat terlihat lalu mengukur panjang tali dan mencatat posisi pengambilan data. Pendapat Effendi (2003) bahwa nilai kecerahan sangat dipengaruhi oleh padatan tersuspensi dan kekeruhan, keadaan cuaca, waktu pengukuran, serta ketelitian orang yang melakukan pengukuran. 


\section{Pengamatan biota berbahaya}

Pengamatan biota berbahaya perlu dilakuakan untuk megetahui ada atau tidaknya biota berbahaya yang akan mengangu pengunjung wisata. Pengamatan biota berbahaya dilakukan berdasarkan snorkeling di sekitar stasiun penelitian (Masita dkk, 2013). Adapun biota berbahaya bagi pengunjung ekowisata diantaranya gastropoda, karang api, landak laut, bulu babi, ubur-ubur , anemon dan ular laut.

\section{Ketersediaan air tawar}

Ketersediaan air merupakan hal penting dalam suatu kehidupan. Tidak hanya untuk sektor rumah tangga, melainkan juga untuk sektor wisata. Pengamatan ketersediaan air tawar dilakukan dengan cara mengukur jarak antara stasiun penelitian dengan lokasi dimana sumber air tawar tersedia (Masita $d k k, 2013)$.

Kegiatan ekowisata, ketersediaan air bersih berupa air tawar sangat diperlukan untuk menunjang fasilitas pengelolaan maupun pelayanan ekowisata. Hal ini juga merupakan menjadi kriteria penilaian terhadap kelayakan prioritas pengembangan ekowisata pantai (Handayawati, 2010).

\section{Analisis Data}

\section{Analisis kesesuaian kawasan}

Analisis kesesuaian kawasan untuk ekowisata pantai memiliki dua kategori yaitu : Kesesuaian Kawasan Untuk Wisata Pantai Rekreasi diantaranya,Kedalaman, Tipe Pantai, Lebar Pantai, Material Dasar Perairan, Kecepatan Arus (m/dt), Kecerahan (m), Biota Berbahaya, Ketersedian Air Tawar (km) (dapat dilihat pada Tabel 3).

Tabel 3. Matriks Kesesuaian Kawasan Untuk Ekowisata Pantai Rekreasi

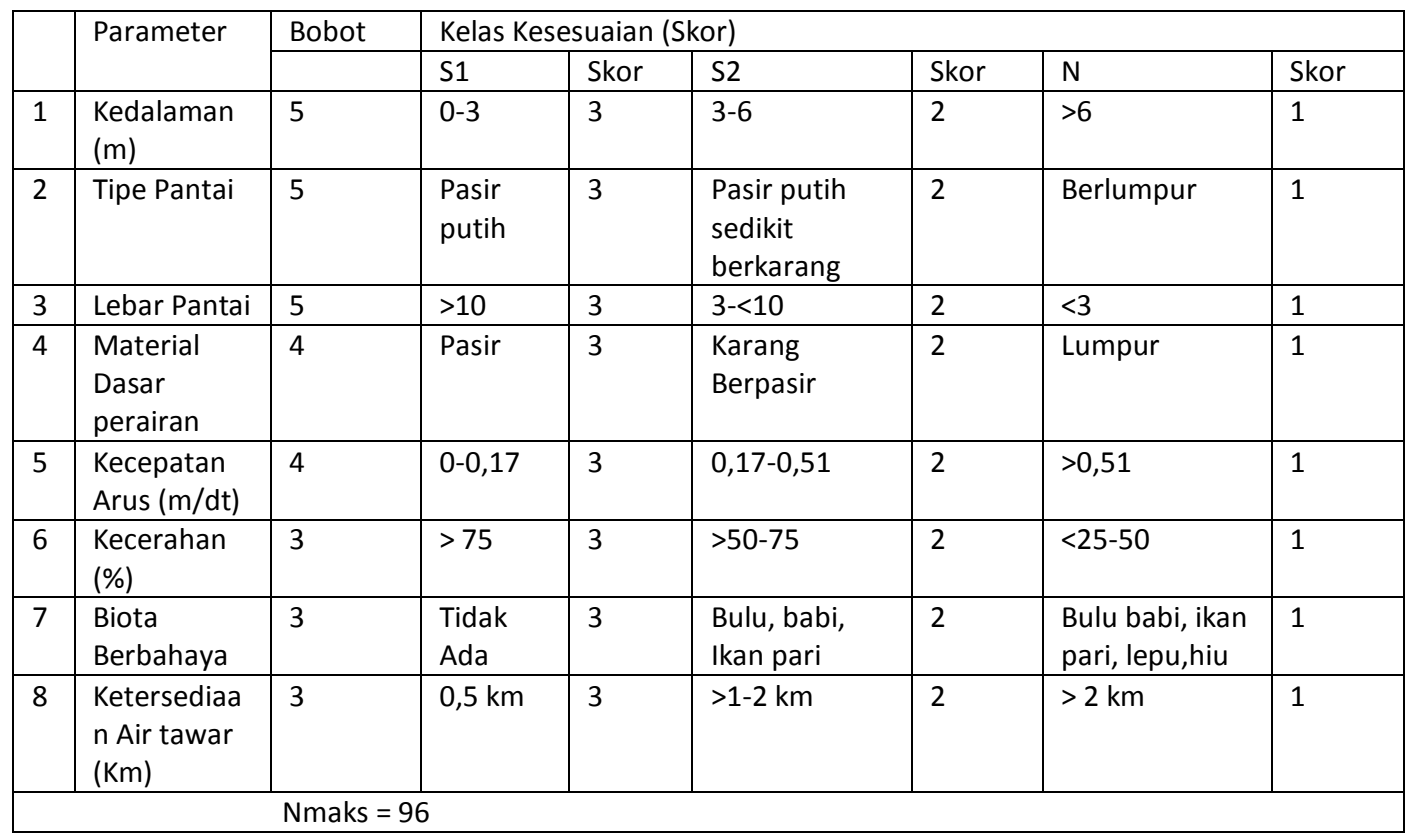

Sumber : Modifikasi Yulianda (2007) 
Keterangan:

Kategori S1

Kategori S2

= Sangat Sesuai

Kategori N

= Sesuai

= Tidak Sesuai

Menurut (Yulianda, 2007) : Rumus yang digunakan untuk kesesuaian wisata pantai adalah:

$$
\mathrm{IKW}=\sum\left[\frac{\mathrm{Ni}] \times 100 \%}{\mathrm{Nmaks}}\right.
$$

Keterangan :

$$
\begin{array}{ll}
\mathrm{IKW}=\text { Indeks } & \text { Kesesuaian Wisata } \\
\mathrm{Ni} & =\text { Nilai total keseluruhan } \\
\mathrm{Nmaks} & =\text { Nilai maksimum dari suatu kategori wisata } \\
\text { (S1) } & =77,78-100 \%, \\
\text { (S2) } & =55,56-<77,78 \%, \\
\text { (N) } & =<55,56 \%
\end{array}
$$

\section{Analisa Daya Dukung Daya Dukung Kawasan}

Daya dukung ekowisata tergolong spesifik dan lebih berhubungan dengan daya dukung lingkungan (biofisik dan sosial) terhadap kegiatan pariwisata dan pengembangannya (McNeely 1994). Daya dukung wisata dapat dihitung dengan rumus (Yulianda, 2010) :

$$
\begin{array}{r}
\mathrm{DDK}=\mathrm{K} \times \underset{\mathrm{Lt}}{\mathrm{Lp}} \times \mathrm{Wt} \\
\mathrm{Wp}
\end{array}
$$

Keterangan :

$$
\begin{array}{ll}
\text { DDK } & \text { = Daya dukung kawasan } \\
\mathrm{K} & =\text { Potensi ekologis pengunjung per satuan unit area } \\
\mathrm{Lp} & \text { = Luas area atau panjang area yang dapat dimanfaatkan } \\
\mathrm{Lt} & =\text { Unit area untuk kategori tertentu } \\
\mathrm{Wt} & =\text { Waktu yang disediakan oleh kawasan untuk kegiatan wisata dalam satu } \\
\mathrm{Wp} & \text { hari } \\
\mathrm{Waktu} \quad \text { yang dihabiskan oleh pengunjung untuk setiap kegiatan. }
\end{array}
$$

Kegiatan ekowisata pantai rekreasi dan olahraga pantai dilihat pada Tabel 4. Diasumsikan setiap orang membutuhkan panjang garis pantai $50 \mathrm{~m}$, karena pengunjung akan melakukan berbagai aktivitas yang memerlukan ruang yang luas, seperti berjemur, bersepeda, berjalan-jalan dan lain-lain.

Tabel 4. Potensi Ekologis Pengunjung dan Luas Area Kegiatan

\begin{tabular}{cccl}
\hline Jenis Kegiatan & $\begin{array}{l}\text { Spengunjung } \\
\text { (orang) }\end{array}$ & Unit Area (Lt) & Keterangan \\
\hline Rekreasi pantai & 1 & $50 \mathrm{~m}$ & $\begin{array}{l}1 \text { org setiap } 50 \mathrm{~m} \\
\text { panjang pantai } \\
1 \text { org setiap } 50 \mathrm{~m} \\
\text { panjang pantai }\end{array}$ \\
Wisata olah raga & 1 & $50 \mathrm{~m}$ &
\end{tabular}

Tabel Potensi Ekologis Pengunjung dan Luas Area Kegiatan dapat dilihat pada Tabel 5. Waktu kegiatan pengunjung $(\mathrm{Wp})$ dihitung berdasarkan lamanya waktu yang dihabiskan oleh pengunjung untuk melakukan kegiatan wisata. Waktu pengunjung diperhitungkan dengan waktu yang disediakan untuk kawasan (Wt) (Tabel 5). Waktu kawasan adalah lama waktu areal dibuka dalam satu hari, dan rata-rata waktu kerja sekitar 8 jam (jam 8 - 16). 
Tabel 5 Potensi Ekologis Pengunjung dan Luas Area Kegiatan

\begin{tabular}{llll}
\hline No. & Kegiatan & Waktu yang Dibutuhkan & Total Waktu 1 Hari \\
& & Wp- (jam) & Wt- (jam) \\
\hline 1. & Berjemur & 2 & 4 \\
2. & Rekreasi Pantai & 3 & 6 \\
\hline
\end{tabular}

Sumber : Yulianda, 2007

\section{HASIL DAN PEMBAHASAN}

\section{Gambaran Umum Lokasi Penelitian}

Desa Merpas terletak di Kecamatan Nasal, secara astronomis terletak pada $4^{\circ} 36^{\prime} 9.9^{\prime \prime}-4^{\circ} 55^{\prime} 27,77^{\prime \prime}$ Lintang selatan dan $103^{\circ} 28^{\prime} 55^{\prime \prime}-103^{\circ}-46^{\prime} 50,12^{\prime \prime}$ Bujur Timur. Berdasarkan letak astronomis tersebut mengambarkan bahwa terjadi pada pertengahan tahun. Batas wilayah administratif Desa Merpas yaitu berbatasan dengan :Batas Utara berbatasan dengan: Desa Batu Lungun, Batas Selatan berbatasan dengan : Desa Pasar Baru, Batas Barat berbatasan dengan : Lautan ( samudera hindia ), Batas Timur berbatasan dengan : Desa Air Batang dan Desa Batu Lungun.

Luas wilayah Kabupaten Kaur adalah $2.556 \mathrm{~km}^{2}$ dengan luas wilayah daratan seluas 236.500 ha yang terdiri dari 15 kecamatan dan 95 desa dan kelurahan. Panjang garis pantai Kabupaten Kaur sepanjang 89 km dengan kawasan laut seluas $660,59 \mathrm{~km}^{2}$ (BPS, 2015)

\section{Iklim dan Cuaca}

Kecamatan Nasal beriklim tropis dan memiliki dua musim yaitu musim hujan dan musim kemarau, musim hujan terjadi pada akhir tahun hingga awal tahun sedangakan pada umumnya musim kemarau (BPS, 2015).

\section{Pasang Surut}

Perairan Kabupaten Kaur memiliki kedalaman berkisar 0-50 m, dengan laut dalam antara 50-300 meter. Hal inilah yang medukung pertumbuhan dan perkembangan perkembangan biota laut di perairan Kabupaten Kaur. Kecepatan arus laut $<28 \mathrm{~cm} /$ detik, arah arus dari barat ke laut kearah tetangga. Arus bergerak ke pantai saat pasang, berbalik kearah laut setelah membentur fitur pantai. Tipe pasang surut tipe campuran dominan semidiurnal, terdapat dua kali pasang dan dua kali surut selama 24 jam (Hazeri, 2014).

\section{Analisis Kesesuain Ekowisata Pantai Kategori Rekreasi}

\section{Kedalaman Perairan}

Kedalaman perairan merupakan aspek yang cukup penting yang diperhitungkan dalam penentuan suatu kawasan untuk dijadikan sebagai kawasan wisata pantai khususnya mandi dan renang karena sangat berpengaruh pada aspek keselamatan pada saat berenang. Secara fisik kedalaman perairan yang dangkal cukup baik untuk dijadikan sebagai objek rekreasi mandi dan renang.

Kegiatan wisata pantai khususnya renang sangat penting untuk keselamatan pada saat berenang. Kedalaman perairan dangkal baik untuk dijadikan sebagai objek rekreasi renang karena tidak berbahaya dibandingkan perairan yang dalam. Kedalaman perairan Pantai Laguna dapat dilihat pada Gambar 2. 


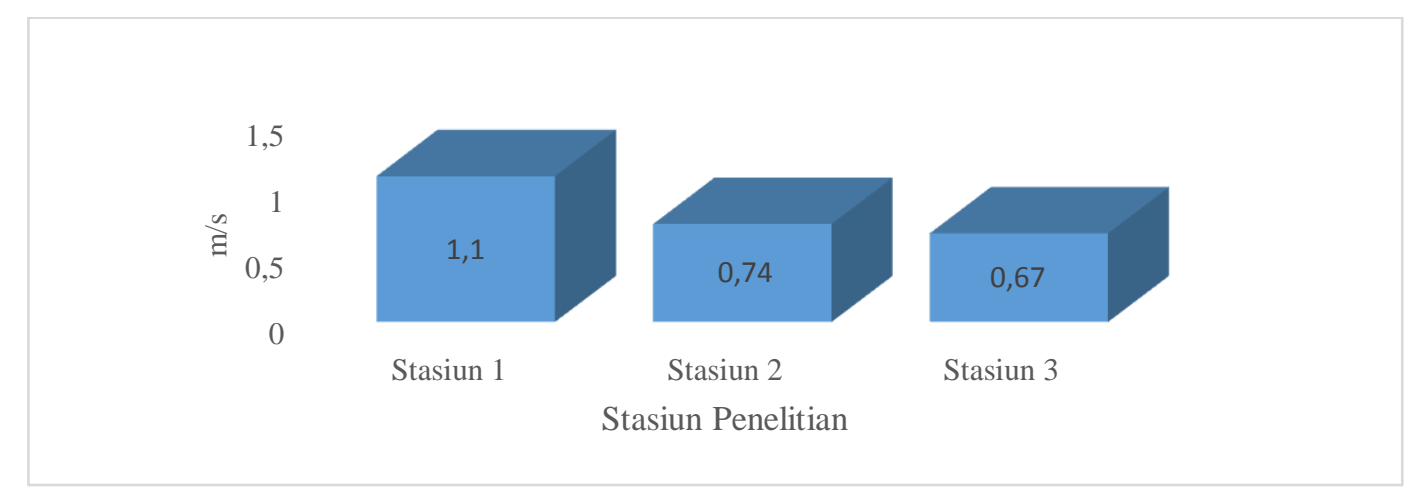

\section{Gambar 2. Grafik Kedalaman Perairan Pantai}

Hasil penelitian Gambar 2 pengukuran kedalaman perairan Pantai Laguna kedalaman perairan relative dangkal dan baik untuk dijadikan untuk objek ekowisata pantai kategori rekreasi terutama mandi dan berenang kedalaman yang baik yaitu berkisar 0-3 meter. Pantai Laguna memiliki kareteristik yaitu ratarata kedalaman 2 meter sehingga dapat disimpulkan bahwa Pantai Laguna sangat sesuai (S1). Dalam hal ini peneliti menyimpulkan kedalaman perairan Pantai Laguna sangat aman untuk kegiatan ekowisata pantai kategori rekreasi terutama mandi dan berenang hal ini sesuai dengan pendapat Widiatmaka, (2007) dalam (Hazeri, 2014) yang memberikan batasan nilai kedalaman untuk kesesuaian kedalaman untuk ekowisata pantai kategori cukup sesuai antara 3-6 meter.

\section{Tipe Pantai}

Berdasarkan hasil penelitian di lapangan Tipe Pantai Laguna adalah Tipe Pantai berpasir dengan sedikit berkarang hal ini sesuai dengan pendapat Yulianda (2007) bahwa untuk wisata pantai akan sangat baik jika suatu pantai merupakan pantai yang berpasir atau dengan kata lain didominasi oleh substrat pasir, dibandingkan dengan pantai yang berbatu atau pantai yang didominasi oleh substrat karang dapat mengganggu kenyamanan wisatawan. Berdasarkan analisis dilapangan butiran sedimen di setiap stasiun di dominasi dengan jenis substrat ukuran sedang. Ukuran sedimen yang kasar dan sedang sangat baik untuk kegiatan ekowisata pantai dibandingkan ukuran butir sedimen yang sangat halus dan kasar (Hazeri, 2014).

Hasil pengamatan secara visual di lapangan pada setiap stasiun dapat dilihat pada (Gambar 3). Bahwa pasir di sepanjang Pantai Laguna merupakan pasir berkarang. Pasir berkarang yang ada di Pantai Laguna memberikan kesan tersendiri bagi pegunjung yang datang ke Pantai Laguna terutama bagi pengunjung yang ingin melakukan rekreasi Pantai. Karang yang ada di Pantai Laguna didominasi dengan bentuk sesuai dengan merayap sesuai gelombang yang besar. Secara visual menurut Pangesti (2007) dalam (Hazeri, 2014) jenis dan warna pasir pada suatu objek ekowisata memberikan nilai tersendiri bagi estetika pantai itu sendiri dimana pantai yang memiliki jenis pasir putih dan pasir hitam yang berukuran sedang sampai kasar sangat diminati oleh para wisatawan. 


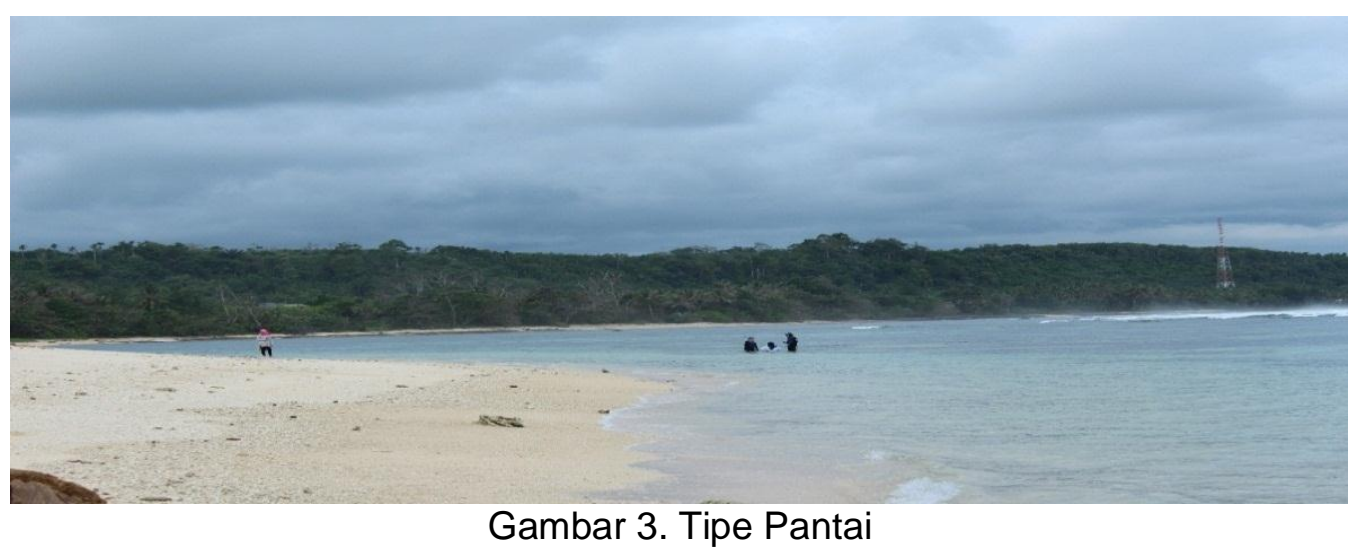

\section{Lebar Pantai}

Kelandaian pantai cenderung mempengaruhi keamanan seseorang untuk melakukan kegiatan wisata pantai seperti mandi dan renang. Pantai datar sampai landai sangat baik untuk kegiatan wisata renang dimana wisatawan dapat melakukan berbagai kegiatan seperti berenang, bermain pasir serta dapat bermain-main dengan ombak di tepinya, menurut bentuknya pantai dapat dibedakan menjadi empat macam yaitu pantai datar, landai, curam dan pantai terjal (Yulianda, 2007). Lebar Pantai Laguna dapat dilihat pada (Gambar 4).

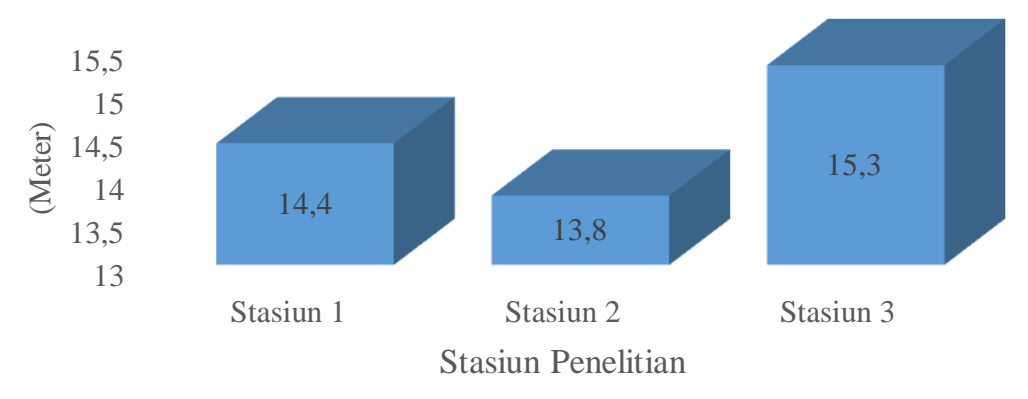

Gambar 4. Lebar Pantai Laguna

Berdasarkan hasil pengamatan di lapangan Lebar Pantai Laguna sangat sesuai untuk dijadikan objek Ekowisata Pantai karena Pantai Laguna memiliki pantai yang landai dimana wisatawan yang datang ke Pantai Laguna bisa bermain pasir, bermain ombak di tepi Pantai. Lebar Pantai Laguna $>10$ menurut pendapat Yulianda (2007) sangat sesuai (S1) jika dijadikan Kawasan Untuk Wisata Pantai Rekreasi.

\section{Material Dasar Perairan}

Material Dasar Perairan/ Substrat merupakan penentu kecerahan suatu perairan. Pengamatan Material Dasar Perairan/ Substrat dilakukan dengan cara melakukan pengamatan langsung dilapangan melihat secara visual pada 3 stasiun penelitian. Berdasarkan hasil dilapangan dapat dilihat pada Gambar 5. Bahwa material dasar perairan/ substrat di Pantai Laguna jenis karang berpasir. Hal ini juga sesuai dengan pendapat Margomgom (2013) dalam (Hazeri, 2014).dengan hasil Material Dasar Perairan/ Substrat di perairan pantai tanjung pesona merupakan pasir. Material Dasar Perairan/ Substrat berwarna putih sangat sesuai untuk dijadikan wisata rekreasi dan berenang. 
Hasil penelitian pengamatan lansung dilapangan juga didukung oleh teori Yulianda (2007) bahwa Material Dasar Perairan/ Substrat yang berwarna putih sangat sesuai (S1) untuk menunjang ekowisata di Pantai Laguna.

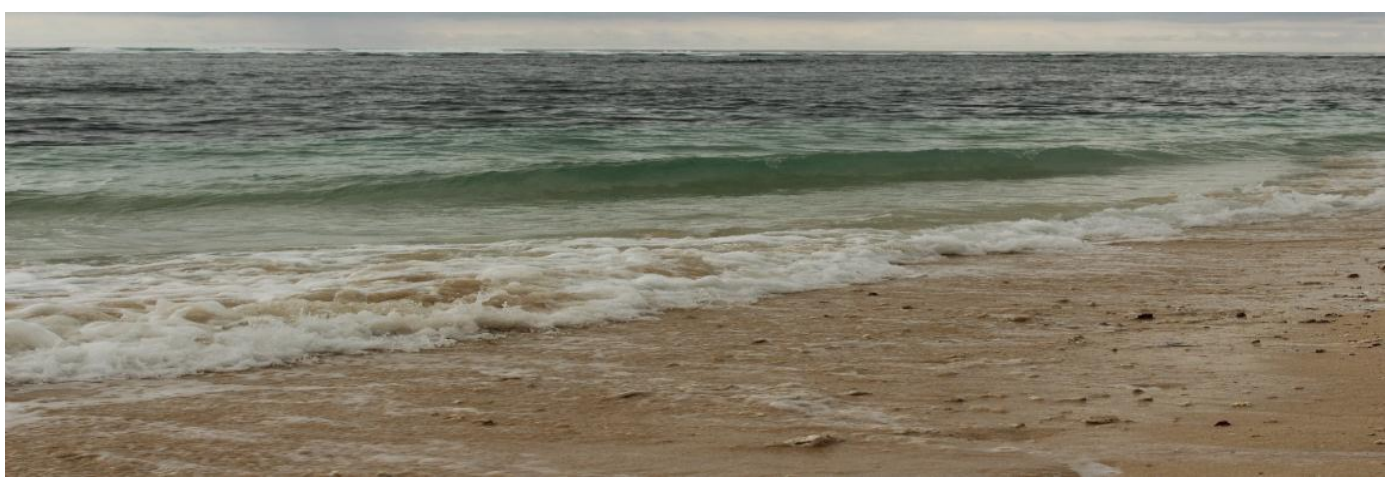

Gambar 5.Material Dasar Perairan Pantai Laguna

\section{Kecepatan Arus}

Nybakken (1992) menyatakan bahwa kecepatan arus sangat erat kaitannya dengan keamanan wisata dalam berenang. Arus yang lemah sangat baik untuk kegiatan renang, sedangkan arus yang sangat kuat berbahaya karena dapat menyeret orang-orang yang sedang mandi atau renang di pantai. Kecepatan arus sangat erat kaitannya dengan keamanan para wisatawan dalam berenang. Arus yang lemah sangat baik untuk kegiatan renang sedangkan arus yang kuat sangat berbahaya karena dapat menyeret orang-orang yang sedang mandi atau renang di pantai. Pengambilan data kecepatan arus dilakukan terlebih dahulu menentukan titik koordinat pada 3 stasiun yang telah ditentukan dengan menggunakan GPS. Kecepatan arus di Pantai Laguna dapat dilihat pada Gambar 6. Berikut :

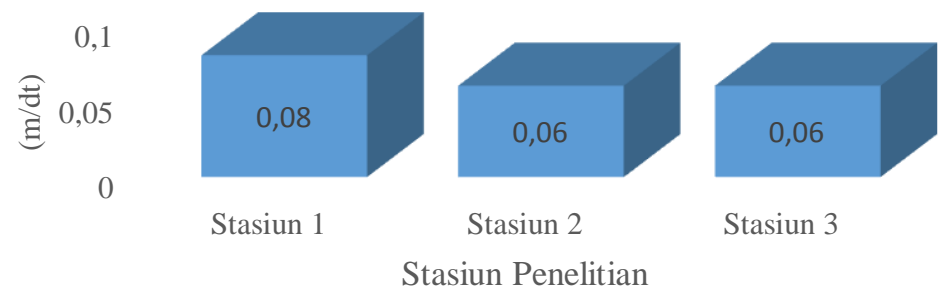

Gambar 6. Kecepatan Arus Pantai Laguna

Berdasarkan hasil penelitian dilapangan pada kecepatan arus Pantai Laguna adalah $0,016(\mathrm{~m} / \mathrm{s})$, dari hasil tersebut dapat disimpulkan bahwa Kecepatan Arus di Pantai Laguna relative kecil dan sangat ideal untuk wisata rekreasi dan berenang hal ini juga didukung berdasarkan Matriks Kesesuaian Kawasan Untuk Wisata Pantai Rekreasi menurut Yulianda (2007) yaitu masuk kategori sangat sesuai (S1), hasil penelitian juga dibandingkan dengan penelitian Cahyadinata (2009) dalam (Hazeri, 2014). kecepatan Arus di Pantai Kaana Pulau Enggano berkisar $0,13 \mathrm{~m} / \mathrm{s}$. kecepatan arus erat kaitannya dengan kenyamanan wisatawan yang datang ke objek wisata tersebut jika arus dalam keadaan kencang sebaiknya pengunjung tidak melakukan aktivitas ekowisata karena akan berbahaya untuk keselamatan pengunjung yang datang, jika kecepatan arus relative tenang akan memberikan kesan kenyamanan bagi wisatawan yang ingin melakukan aktivitas ekowisata. 


\section{Kecerahan}

Effendi (2003) megemukan bahwa Nilai kecerahan sangat dipengaruhi oleh padatan tersuspensi dan kekeruhan, keadaan cuaca, waktu pengukuran, serta ketelitian orang yang melakukan pengukuran. Kecerahan perairan dalam kaitannya dengan kegiatan ekowisata pantai sangat berperan dalam hal kenyamanan para wisatawan pada saat berenang. Pengukuran kecerahan dilakukan dengan menggunakan secchi disk yang diikat dengan tali kemudian diturunkan perlahan-lahan ke dalam perairan pada lokasi pengamatan sampai pada batas visual secchi disk tersebut tidak dapat terlihat lalumengukur panjang tali danmencatat posisi pengambilan data. Kecerahan Pantai Laguna dapat dilihat pada Gambar 7. Kecerahan Perairan Pantai Laguna.

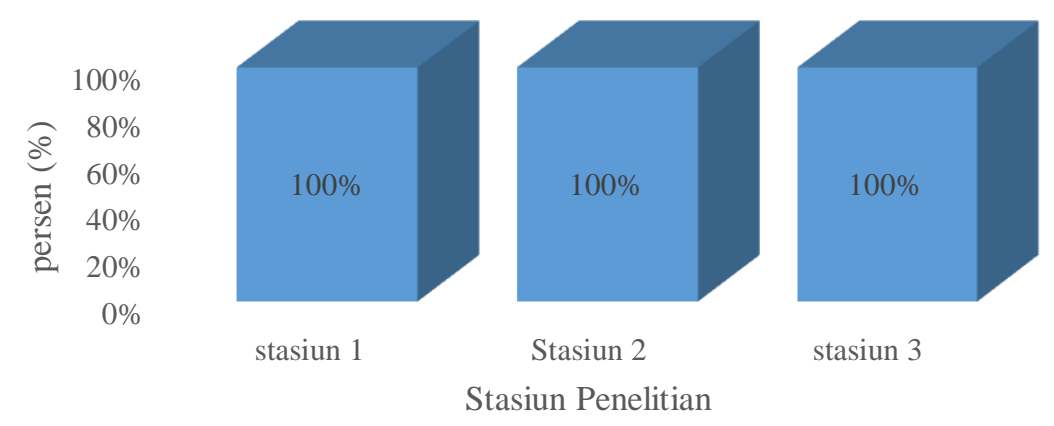

Gambar 7. Kecerahan Perairan Pantai Laguna.

Berdasarkan hasil pengukuran kecerahan di lapangan kecerahan di perairan Pantai Laguna yaitu $100 \%$ hal ini juga di dukung oleh penelitian (Hazeri, 2014). dikarenakan banyak nya aktivitas -aktivitas yang intensif di sekitar area wisata. Maka dapat disimpulkan kecerahan perairan di Pantai Laguna sangat ideal untuk Wisata Rekreasi dan Berenang. Hasil penelitian ini juga sama dengan Cahyadinata (2009) yang melakukan penelitian di Pantai Kaana Pulau Enggano, dasar perairan masih tampak dengan pengamatan visual. Begitu juga hal nya di Pantai Laguna yang diamati langsung oleh peneliti bahwa dasar Perairan di Pantai Laguna masih tampak dilihat dengan pengamatan visual.

\section{Pengamatan Biota Berbahaya}

Pengamatan biota berbahaya perlu dilakukan untuk megetahui ada atau tidaknya biota berbahaya yang akan mengangu pengunjung wisata. Pengamatan biota berbahaya dilakukan berdasarkan snorkeling di sekitar stasiun penelitian (Masita, 2013). Adapun biota berbahaya bagi pengunjung wisata diantaranya gastropoda, karang api, landak laut, bulu babi, ubur-ubur, anemon dan ular laut.

Berdasarkan pengamatan langsung di lapangan dengan melakukan snorkeling di ketiga stasiun yang telah ditentukan, tidak ada biota berbahaya di Perairan Pantai Laguna dapat disimpulkan bahwa menurut teori Yulianda (2007) masuk kategori sangat sesuai (S1) untuk Kesesuaian Kawasan Untuk Wisata Pantai Rekreasi. Akan tetapi berdasarkan hasil wawancara kepada penjaga yang tinggal di sekitar area ekowisata Pantai Laguna mengatakan bahwa adanya biota berbahaya di Pantai Laguna tergantung musiman. Kalaupun ada bulu babi, wisatawan yang datang dapat melihat langsung karena kecerahan Material Dasar perairan Pantai Laguna nampak dengan penglihatan visual.

\section{Jarak Ketersedian Air Tawar}


Ketersediaan air merupakan hal penting dalam suatu kehidupan. Tidak hanya untuk sektor rumah tangga, melainkan juga untuk sektor wisata. Pengamatan ketersediaan air tawar dilakukan dengan cara mengukur jarak antara stasiun penelitian dengan lokasi dimana sumber air tawar tersedia dapat dilihat pada Gambar 8.

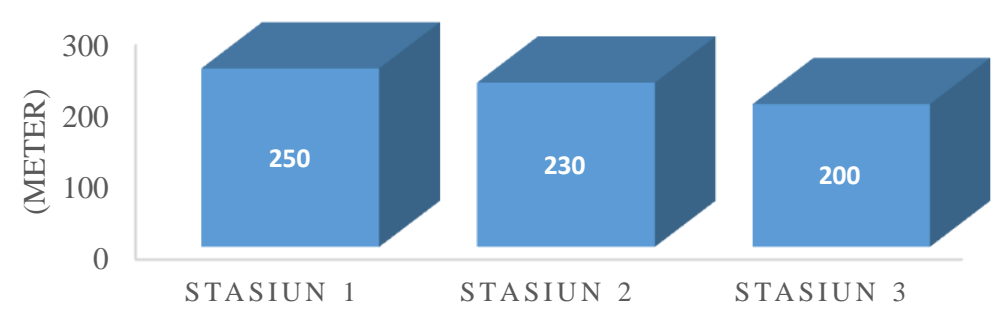

Gambar 8. Ketersediaan Air Tawar

Berdasarkan hasil penelitian di lapangan jarak antara Ketersedian Air Tawar yaitu stasiun $1(250 \mathrm{~m})$ stasiun $2(230 \mathrm{~m})$ stasiun $3(200 \mathrm{~m})$. Hal ini jika dilihat menurut Matriks Kesesuaian Kawasan Untuk Wisata Pantai Rekreasi Yulianda (2007) Jarak Ketersedian Air Tawar antara lokasi area wisata sangat sesuai (S1) yaitu $0,5 \mathrm{~km}$.

Saat melakukan Kegiatan wisata, ketersediaan air bersih berupa air tawar sangat diperlukan untuk menunjang fasilitas pengelolaan maupun pelayanan wisata. Hal ini juga merupakan menjadi kriteria penilaian terhadap kelayakan prioritas pengembangan wisata pantai (Handayawati, 2010).

\section{Analisis Kesesuaian Kawasan Ekowisata Rekreasi}

Hasil pengukuran yang telah di peroleh dilapangan yaitu ada 3 stasiun penelitian. Peneliti menganalisis kesesuaian berdasarkan aspek penilaian yang disesuaikan dalam Tabel paremeter kesesuain ekowisata pantai rekreasi, menghitung analisis kesesuaian kawasan berdasarkan (Yulianda, 2007). Hasil analisis kesesuaian ekowisata dan kesesuaian kawasan pantai kategori rekreasi dapat dilihat pada (Tabel 6).

Tabel 6. Hasil analisis kesesuaian kawasan pantai kategori rekreasi.

\begin{tabular}{lll}
\hline Stasiun & IKW & Kategori \\
\hline Stasiun I & $90,6 \%$ & S1(Sangat Sesuai) \\
Stasiun II & $90,6 \%$ & S1(Sangat Sesuai) \\
Stasiun III & $90,6 \%$ & S1(Sangat Sesuai) \\
\hline
\end{tabular}

Nilai indeks kesesuaian wilayah ekowisata Pantai Laguna pada Tabel. 6 menunjukan tingkat kelayakan ekowisata Pantai Laguna sebagai kesesuaian kawasan ekowisata Pantai Laguna dijadikan sebagai suatu objek ekowisata pantai . Hal ini memiliki nilai penting terhadap pengelolaan suatu ekowisata. Berdasarkan hasil penelitian analisis kesesuaian lokasi ekowisata pada ketiga Stasiun didapatkan nilai 90,6 \% atau berada pada kategori S1: dengan nilai 75 $100 \%$ (Sangat Sesuai), nilai indeks yang sama pada ketiga stasiun dikarenakan jarak antar stasiun penelitian hanya $100 \mathrm{~m}$ oleh karena itu hasil penelitian dilapangan dari paremeter yang diukur tidak jauh berbeda pada antar stasiun penelitian yang diukur, sama halnya pada penelitian (Cahyadinata, 2009) nilai indeks kesesuaian kawasan (IKW) yaitu 97.4\% (Sangat Sesuai) di pantai Kaana pulau Enggano Ini berarti, pantai Kaana bagus (sangat sesuai) dikembangkan untuk pariwisata pantai Hasil penelitian ini juga sama dengan penelitian 
(Nugraha, dkk 2012) kawasan untuk Wisata Rekreasi Pantai di Pantai Panjang Kota Bengkulu memiliki kategori sangat sesuai (S1) (IKW) yaitu : 86,90\% (Sangat Sesuai) terdapat di Kecamatan Ratu Samban sedangakan nilai indeks kesesuaian kawasan (IKW) yaitu 82,14\% (Sangat Sesuai) (S1) di Kecamatan Teluk Segara.

\section{Analisis Daya Dukung Kawasan}

Daya dukung ekowisata sangat penting untuk menjaga suatu lingkungan secara berkelanjutan terhadap kegiatan suatu ekowisata. Hasil analisis daya dukung kawasan Pantai Laguna dapat dilihat pada (Tabel 7).

Tabel 7. Hasil analisis daya dukung kawasan Pantai Laguna

\begin{tabular}{lll}
\hline No & Kegiatan Wisata & DDK (Orang / hari) \\
\hline 1 & Rekreasi pantai & 224
\end{tabular}

Berdasarkan Hasil analisis daya dukung kawasan ekowisata pantai laguna daya dukung kawasan ekowisata rekreasi yaitu 224 (Orang/hari). Hal ini tidak jauh berbeda dengan penelitian Ramadhan, dkk (2014) daya dukung di kawasan Pantai Cermin adalah 260 orang/hari. Dibandingkan dengan jumlah pengunjung yang datang ke pantai tersebut berkisar 85 orang/hari. Sehingga dapat disimpulkan bahwa pantai ini dapat menampung seluruh kegiatan wisata yang dilakukan para pengunjung dengan baik tanpa melebihi daya dukung kawasan sehingga pantai ini kelestariannya tetap terjaga.

\section{KESIMPULAN DAN SARAN}

\section{Kesimpulan}

Potensi ekowisata pantai di Pantai Laguna salah satunya adalah ekowisata kategori rekreasi, dengan nilai indeks kesesuaian kawasan (IKW) 90,6\% S1 (sangat sesuai), daya dukung kawasan ekowisata pantai kategori rekreasi 224 (Orang/hari).

\section{Saran}

Penelitian lebih lanjut terkait dengan daya dukung kawasan sebaiknya yaitu dengan mengunakan sistem informasi dan geografis agar data yang didapat lebih akurat dan dapat digunakan sesuai dengan peruntukan ruang yang ada. diharapkan kepada stake holder terkait dapat mengembangkan dan memfasilitasi ekowisata Pantai Laguna dengan lebih baik agar dapat dikembangkan menjadi pariwisata unggulan Kabupaten Kaur.

\section{DAFTAR PUSTAKA}

Ali, D. 2004. Pemanfaatan Potensi Sumberdaya Pantai Sebagai Obyek Wisata Dan Tingkat Kesejahteraan Masyarakat Sekitar LokasiWisata (Studi Kasus Di Kawasan Wisata Pantai Kartini Jepara).Program Pascasarjana Universitas Diponegoro. Semarang

Badan Pusat Statistik Kabupaten Kaur.2015.Data Kecamatan Nasal Kabupaten Kaur.Kaur.Badan Pusat Statistik Kabupaten Kaur. 
Budhyana, I. 2008. Kebijakan Disbudpar dalam Mengembangkan Kawasan Wisata di Jawa Barat. Makalah pada Seminar Pembangunan Kepariwisataan di Jawa Barat., Bandung: UPI

Cahyadinata, I. 2009. Kesesuaian Pengembangan Kawasan Pesisir Pulau Enggano Untuk Pariwisata dan Perikanan Tangkap.Bengkulu. Jornal Agrisep Vol.9 No.2,Maret 2009 Hal 168-182.

Effendi, H. 2003. Telaah Kualitas Air bagi Pengelolaan Sumberdaya dan Lingkungan Perairan. Kanisius. Yogyakarta. 258 halaman.

Fandeli, C.M. 2000. Pengusaha Ekowisata. Gajah Mada University Press. Yogyakarta

Hazeri, G. 2014. Studi Kesesuaian Pantai Laguna Desa Merpas Kecamatan Nasal Kabupaten Kaur Sebagai Daerah Pengembangan Pariwisata dan Konservasi. Skripsi.Fakulatas Pertanian. Universitas Bengkulu, Bengkulu (tidak dipublikasikan).

Handayawati, H. 2010. Potensi Wisata Alam Pantai-Bahari. PM PSLP PPSUB.

Kementrian Kebudayaan dan Pariwisata Republik Indonesia. 2002. Blue Print Pariwisata. Jakarta: Kementerian Kebudayaan dan Pariwisata.

Marpaung. 2002. Pengetahuan Kepariwisataan. Bandung: Afabeta.

Masita H.K, Femy M.S, Sri N.H,. 2013. ( Jurnal) Kesesuaian Wisata Pantai Berpasir Pulau Saronde Kecamatan Pondo Kepulauan Kabupaten Gorontalo Utara.

McNeely JA. 1994. An Introduction to Protected Area Economics and Policy (In: Protected area Economics And Policy, Munasinghe, M and J. McNeelye eds. 111)The Worl Bank, Washington DC.

Nugraha, H.P, Agus I, Muhammad H,. 2012. Studi Kesesuaian dan Daya Dukung Kawasan untuk Rekreasi Pantai di Pantai Panjang Kota Bengkulu. Journal Of Marine Research Vol.2, No 2 Tahun 2013, Hal130-139.

Nybakken, J.W. 1992. Biologi Laut.Suatu Pendekatan Ekologis.Gramedia, Jakarta.

Safina., Pindi,P., Ahmad,M,. 2014. Analisis Potensi dan daya dukung kawasan wisata pantai cermin kabupaten serdang bedagai. Program studi manajaemen sumber daya perairan Fakultas pertanian, Universitas Sumatera Utara.

Ramadhan, S., Pindi. P., Zulham. A.H. 2014. Analisis Kesesuaian dan Daya Dukung Kawasan Wisata Pantai Cermin Kabupaten Serdang Begadai. Fakultas Pertanian USU.Sumatera Utara.

Yulianda, F. (2007). Ekowisata Bahari Sebagai Alternatif Pemanfaatan Sumberdaya

Yulianda, F. A. Fahrudin, A. A.Hutabarat, S. Harteti, Kusharjani. Kang, S. H. 2010. 